\title{
CHANGES IN BIOCHEMICAL PARAMETERS IN HUMAN IMMUNODEFICIENCY VIRUS INFECTED PATIENTS: A PRE-TREATMENT STUDY
}

\section{Ochalefu $\mathrm{DO}^{I^{*}}$, Abu $\mathrm{HA}^{2}$, Amali OOE ${ }^{1}$, Agada $\mathrm{SA}^{1}$, Alonyenu EI.}

Department of Medical Biochemistry, College of Health Sciences, Benue State University, Makurdi, Nigeria. ${ }^{1}$

Department of Veterinary Physiology, Pharmacology and Biochemistry, College of Veterinary Medicine, University of

Agriculture, Makurdi, Nigeria. ${ }^{2}$

*Correspondence Author: Dr. Ochalefu, Dickson Owoicho,Department of Medical Biochemistry, College of Health Sciences, Benue State University, Makurdi, Nigeria.Email: dickochalefu@gmail.com.

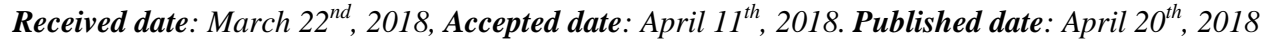

\begin{abstract}
In recent times there have been advances in the management of Human Immunodeficiency Virus infection. However, the disease still poses threat to biochemical parameters of the body. This study was carried out to investigate the biochemical parameters in Human Immunodeficiency Virus infected patients who were yet to start anti-Retroviral drugs regimen. This study was carried out for a period of six weeks using structural questionnaires. A total of one hundred participants were used for the study out of which fifty were Human Immunodeficiency Virus infected while the remaining fifty were Human Immunodeficiency Virus negative, who served as control. There were significant differences $(\mathrm{p}<0.05)$ in the values of Total Protein, Albumin, Alkaline Phosphatase, Aspartate aminotransferase, Alanine aminotransferase, Total Cholesterol, High Density Lipoprotein Cholesterol, Triacylglycerol, Calcium and Sodium of Human Immunodeficiency Virus positive patients when compared with the control. However, there were no significant differences $(p>0.05)$ between the mean values of the conjugated Bilirubin, Urea, Creatinine, Potassium, Bicarbonate and Chloride of the infected patients when compared with those of the control. The findings in this study showed significant changes in biochemical parameters in Human Immunodeficiency Virus infected subjects.
\end{abstract}

Keywords: Antiretroviral drugs, Biochemical parameters, Human immunodeficiency virus.

\section{Introduction}

Human immunodeficiency virus (HIV) infection implies that a person has been infected by the human immunodeficiency virus which breaks down the body's immune system; infects CD4+ initially and progressively leads to Acquired Immune Deficiency Syndrome (AIDS) which is the terminal phase of the disease. ${ }^{1,2,3,4}$ HIV infection produces a slow but progressive and deadly immune suppression which lead to opportunistic infections, neurological disorders and malignancies. This is as a consequence of progressive depletion of the body's cells bearing the cluster of differentiation 4 (CD4+) molecule particularly the helper / inducer subsets of $\mathrm{T}$ lymphocytes, monocytes and macrophages. ${ }^{5,6}$ This ailment is one of the most important emerging infections. It is probably one of the ailments with multiple impacts on persons, families, communities and the entire society. ${ }^{7}$

HIV infection has been reported to cause diverse degree of immunopathogenesis in man and this causes huge biochemical and haematological consequences $^{\left[{ }^{[7]}\right.}$ The infection affects body organs like the liver and the kidneys, there by altering their normal functions. HIV- associated nephropathy characterized by proteinuria, hypoalbuminuria and occasionally hypocalcaemia have been reported. ${ }^{8,9}$ 
Before Highly Active Anti-Retroviral Therapy (HAART) where made available studies on HIVinfected individuals have shown a variety of lipid abnormalities; low levels of Total Cholesterol, High Density Lipoprotein-Cholesterol, Low Density Lipoprotein-Cholesterol and high level of Triacylglycerol ${ }^{10,11,12}$

Abnormal levels of liver enzymes are widespread among persons infected with HIV. Their diagnosis or management may be difficult because of the perplexity involved in pathogenic mechanisms of liver functioning. In many HIV-positive patients with increased level of liver enzymes, the increase is not explained by an identified underlying liver disease or toxin and thus may directly happen either due to antiretroviral drug toxicity or the HIV infection itself ${ }^{13,14,15,16}$ Also, liver enzymes abnormalities in HIVinfected persons may reflect concurrent hepatitis $\mathrm{B}$ (HBV) or hepatitis C (HCV) infection which occur more among HIV positive than HIV negative individuals. ${ }^{16,17,18}$ Other factors that independently contribute to liver damage that may be common in HIV- infected persons include alcohol related liver disease, non-alcoholic steato-hepatitis associated with metabolic syndromes and medication or unlawful drug use. ${ }^{16,19}$

The transmission route of HIV is still commonly sexual (87.4\%). Other routes of transmission by order of proportion include pre-natal/antenatal $(4.7 \%)$, unsafe blood products $(1.7 \%)$, infected needles and syringes $(1.8 \%)$ and unspecified routes of transmission $(4.1 \%){ }^{20,}{ }^{21}$ Also a body of scientific evidence has revealed that men who are circumcised are less likely to contact HIV than men who are uncircumcised. Furthermore, the sex hormones estrogen and progesterone have been found to selectively impact HIV transmission. ${ }^{22}$

HIV infection was once nearly always a fatal diagnosis. However, in recent years, advancements in medicine have transformed this deadly virus into manageable condition, especially when the infection is detected and treatment commenced early enough. The advent of HAART, a cocktail of nucleoside and non-nucleoside analogues with ability to inhibit HIV reverse transcriptase and proteases has led to a diminished progression of the HIV infection to AIDS. This has resulted in improved quality of life of people with HIV infections. The availability of this potent antiretroviral therapy has changed the 'face' of the HIV/AIDS epidemic. It has led to dramatic reduction in AIDS related complications and death. The antiretroviral therapy has transformed the perception of HIV/AIDS from a plague to a manageable chronic illness ${ }^{23,24,25,26}$

Currently no effective HIV vaccine exists. Various HIV vaccines have been tested in clinical trials almost since the discovery of HIV. But after over 20 years of research, HIV-1 remains a hard target for a vaccine $^{.27}$ The HIV infection is associated with background biochemical and haematological abnormalities in infected persons ${ }^{7}$ This study was designed with the aim to determine the biochemical parameter of pre-treatment HIV infected persons in Makurdi, Benue State, Nigeria.

\section{Materials and Method}

A total of one hundred persons comprising of fifty patients confirmed to be HIV- positive but yet to commence highly active antiretroviral therapy and fifty persons confirmed to be negative for HIV antibodies were randomly selected from the HIV/AIDS clinic and the blood bank of the Federal Medical Centre, Makurdi respectively. The participants confirmed negative for HIV were blood donors at the blood bank who were used as the control subjects. The HIV status of the participants was confirmed using Western Blot. The subjects were made up of adults of both sexes. The purpose and nature of the research were explained to the participants and they gave their consent. A structural questionnaire was filled by the subjects in order to obtain their demographic data and clinical history and assistance was given on request. The following criteria were put into consideration in the selection of the subjects:

1. The control subjects had no hepatitis B, $\mathrm{C}$ or E.

2. No past history suggestive of liver or renal diseases.

\section{Ethical Consent}

The study was approved by the Ethical Committee on Research of the Federal Medical Centre, Makurdi, Benue State, Nigeria. 


\section{Sample Collection}

Five milliliters of blood sample each were collected by venepuncture from the subjects. The site of collection was first sterilized with cotton wool soaked in $70 \%$ alcohol. The blood samples were collected with minimum stasis (to prevent haemolysis) using disposable syringes and needles; and were delivered into plain sample bottles. They were allowed to stand at room temperature for the blood to clot and retract. The clotted samples were then centrifuged at 4000 rpm for 4 minutes and analyzed within twenty- four hours. Universal safety measures were taken into consideration in handling the blood samples.

\section{Biochemical Investigation}

An Automated Clinical Chemistry Analyser (Hitachi 902 Roche Diagnostic GMBH Mannheim, Germany) was used to analyze total serum protein, albumin, total and conjugated bilirubin, alkaline phosphatase, serum aminotransferase, urea, total cholesterol, high density lipoprotein cholesterol (HDL-C), triacylglycerol and calcium. Sodium and potassium cations were estimated using the Flame Photometer. Back titration methods, using modified Vanslyke (1932) was used to estimate bicarbonate ion. Chloride ion was estimated using the modified mercuric nitrate tritrimetric method of Scales and Scales (1971). Fredwald equation was used for the estimation of the values of low density lipoprotein cholesterol (LDL-C) and very low density lipoprotein cholesterol (VLDL-C).

\section{Statistical Analysis}

The data generated for all the biochemical parameters were analyzed for mean \pm standard deviation. The level of significance was set at $p<0.05$ confidence limit using paired student's t- test.

\section{Results}

The results show that serum Total Protein, Alkaline Phosphatase, Aspartate aminotransferase and Alanine aminotransferase in the HIV- positive subjects increased significantly $(\mathrm{p}<0.05)$ when compared to the control. Albumin level in the HIV positive subjects decreased significantly $(p<0.05)$ when compared with the control. There was no significant difference $(p<0.05)$ in the levels of total Bilirubin, Conjugated Bilirubin, Urea and Creatinine in the HIV positive subjects when compared with the control (Table

$1)$.

Table 1: Serum levels of total protein, albumin, and other biochemical parameters in HIV-positive subjects

\begin{tabular}{lll}
\hline Parameters & Control & HIV-positive \\
\hline Total Protein $(\mathrm{g} / \mathrm{L})$ & $83.35 \pm 6.46$ & $87.52 \pm 9.26^{*}$ \\
Albumin $(\mathrm{g} / \mathrm{L})$ & $44.91 \pm 3.38$ & $38.74 \pm 3.80^{*}$ \\
Total Bilirubin $(\mu \mathrm{moL})$ & $10.03 \pm 3.45$ & $10.76 \pm 5.54$ \\
Conjugated Bilirubin $(\mu \mathrm{mol} / \mathrm{L})$ & $2.05 \pm 0.89$ & $2.68 \pm 1.62$ \\
Urea $(\mathrm{mMol} / \mathrm{L})$ & $3.14 \pm 1.29$ & $3.10 \pm 1.10$ \\
Creatinine $(\mu \mathrm{mol} / \mathrm{L})$ & $100.53 \pm 19.82$ & $101.09 \pm 7.23$ \\
Alkaline Phosphatase $(\mathrm{IU} / \mathrm{L})$ & $73.26 \pm 24.63$ & $103.60 \pm 36.46^{*}$ \\
Aspartate aminotransferase $(\mathrm{IU} / \mathrm{L})$ & $31.84 \pm 7.93$ & $35.34 \pm 14.14^{*}$ \\
Alanine aminotransferase $(\mathrm{IU} / \mathrm{L}$ & $24.84 \pm 7.30$ & $28.20 \pm 17.16^{*}$ \\
\hline
\end{tabular}

Values are mean \pm SD.

The superscript '*' indicates significant difference in the results of the HIV positive subjects when compared with the control subjects at $\mathrm{p}<0.05$

The values of Total Cholesterol, Low Density Lipoprotein Cholesterol increased significantly $(\mathrm{p}<0.05)$ in the HIV- positive subjects when compared with the control. High Density Lipoprotein Cholesterol, Very Low Density Lipoprotein Cholesterol and Triacylglycerol levels in the HIV-positive subjects, however, decreased significantly $(\mathrm{p}<0.05)$ when compared with the control subjects (Table 2$)$. 
Table 2: Serum levels of total cholesterol and other lipid components in HIV positive and normal subjects

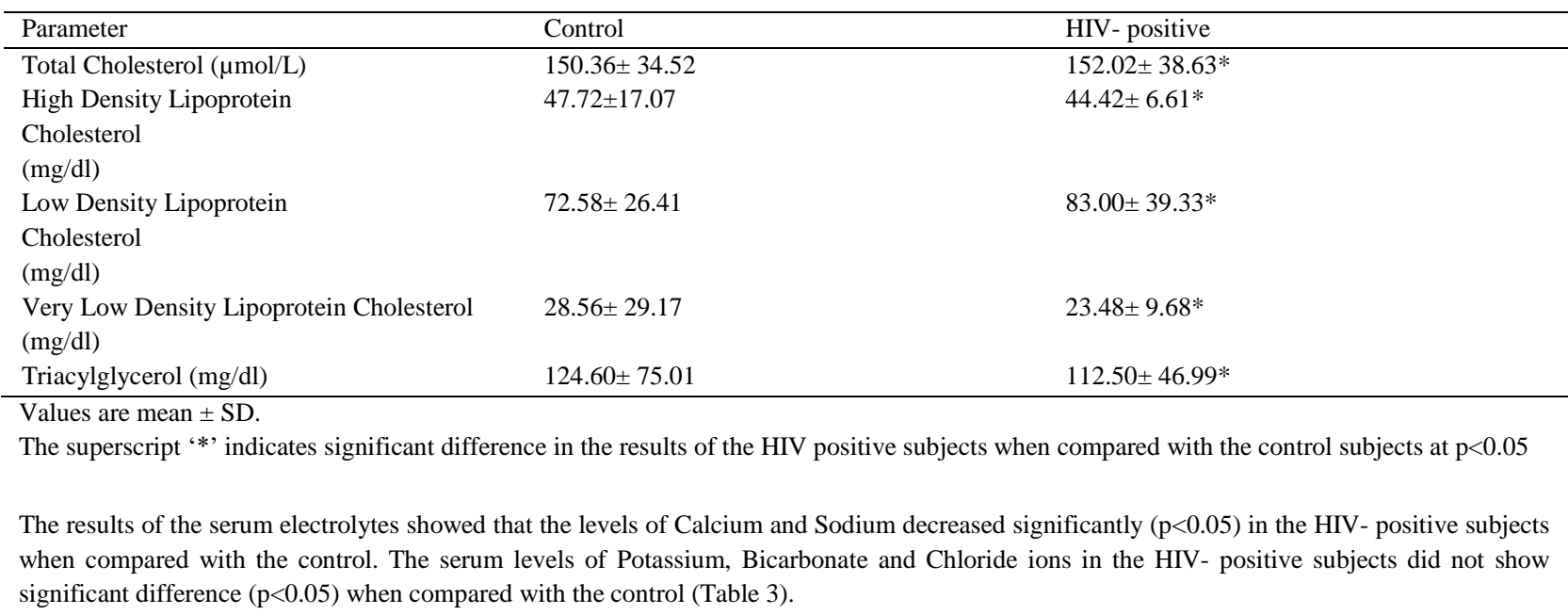

Table 3: Serum levels of electrolytes in HIV positive and normal subjects

\begin{tabular}{lll}
\hline Parameter & Control & HIV-Positive \\
\hline Calcium $(\mathrm{mMol} / \mathrm{L})$ & $4.23 \pm 0.81$ & $3.48 \pm 0.96^{*}$ \\
Sodium $(\mathrm{mMol} / \mathrm{L})$ & $143.40 \pm 3.03$ & $137.88 \pm 2.03^{*}$ \\
Potassium $(\mathrm{mMol} / \mathrm{L})$ & $4.03 \pm 7.15$ & $4.00 \pm 0.69$ \\
Bicarbonate $(\mathrm{mMol} / \mathrm{L})$ & $24.30 \pm 1.31$ & $24.42 \pm 1.58$ \\
Chloride $(\mathrm{mMol} / \mathrm{L})$ & $99.54 \pm 1.63$ & $98.06 \pm 2.39$ \\
\hline
\end{tabular}

Values are mean \pm SD.

The superscript ' $*$ ' indicates significant difference in the results of the HIV positive subjects when compared with the control subjects at $\mathrm{p}<0.05$

\section{Discussion}

This study shows abnormalities in some biochemical parameters in HIV-infected participants when compared with the normal control. The increase serum total protein as observed in this study is in consonance with the work done by Ene et al in which they analysed some biochemical parameters in 81 HIV patients at the University of Maiduguri Teaching Hospital and found elevated serum Total Protein. ${ }^{28}$

The result on Albumin in the present study agrees with the findings of Ranjit and Uplabdhi, Ogunro et al and Drain et al in which they found the level of serum Albumin to decrease significantly $(p<0.05)$ in HIV infected persons when compared with normal control. $^{29,30,31}$ The significant decrease in the Albumin level in the HIV infected patient may be due to impaired liver function capacity to synthesize Albumin due to pathological changes in the liver in HIV infection. Low Albumin level after HIV seroconversion is associated with faster HIV disease progression. $^{29}$

Our results of non-significant difference in the levels of Total Bilirubin, Conjugated Bilirubin, Urea and
Creatinine of the HIV positive patients when compared with the control disagree with the findings of Sarro et al and Magak and Szcech who found significant rise in these parameters in HIV positive patients who presented with associated nephropathy when compared to the healthy control. ${ }^{33,34,35}$ The nonsignificant difference in Urea and Creatinine observed in this study may indicate normal functional and intact kidney in these patients probably because the disease is in its early stage ${ }^{.7}$ Serum Creatinine assessment is recommended as a component of the screening panel for monitoring kidney function and a persistent rise in serum Creatinine is indicative of reduced Creatinine clearance resulting from impaired kidney function ${ }^{33}$

The significant rise in the serum levels of Aspartate aminotransferase, Alanine aminotransferase and Alkaline Phosphatase in the HIV positive subjects is in consonance with the results of Mahendra et al and Palamsany et al where they assessed the serum levels of these enzymes in HIV positive patients and found significant increase in their levels when compared to normal healthy control. ${ }^{21,35}$ The elevated liver 
enzymes in HIV infected patients might be due to direct inflammation of hepatocytes by HIV through apoptosis, mitochondrial dysfunction and permeability alteration in mitochondrial membrane that stimulate an inflammatory response. ${ }^{15}$

In various forms of liver disease, serum levels of numerous cytosolic, mitochondrial and membrane associated enzymes are increased. The degree of elevation varies with the type of disease. Aspartate aminotransferase, Alanine aminotransferase and Alkaline Phosphatase are the enzymes that are most often measured for evaluation of liver disease. The knowledge of intracellular location of enzymes can, therefore, assist in the determination of the nature and severity of a pathological process if suitable enzymes are assayed in the blood ${ }^{21}$

The lipid profile abnormalities in HIV positive subjects seen in this study concur with the work of Adewole et al in which they found significant decrease $(p<0.05)$ in High Density Lipoprotein Cholesterol and significant increase in Low Density Lipoprotein Cholesterol in HIV positive subjects compared with the normal healthy control. ${ }^{36}$ However, the findings of significant increase $(\mathrm{p}<0.05)$ in Total Cholesterol and significant decrease in Triacylglycerol in the HIV-positive subjects contrasts with their findings where they found significant decrease in Total Cholesterol and significant increase in Triacylglycerol when compared with the control. ${ }^{36}$

Bernal et al in their study of lipid profile in HIV infected subjects found a significant decrease $(\mathrm{p}<0.05)$ in Low Density Lipoprotein Cholesterol compared with the healthy normal subjects in contrast to significant increase in Low Density Lipoprotein Cholesterol seen in this study. ${ }^{37}$

Chronic inflammation associated with HIV infection can alter lipid profile in HIV infection ${ }^{38}$ Elevated serum Cholesterol (Hypercholesterolaemia) and Low Density Lipoprotein Cholesterol are high risk factors for coronary heart disease. High serum level of Cholesterol contributes to the formation of atherosclerotic plagues in arteries throughout the body. Low Density Lipoprotein Cholesterol is the major carrier of Cholesterol in the body. It, therefore, increases the risk associated with Cholesterol in coronary heart disease. The low level of High Density Lipoprotein Cholesterol observed in the HIV positive subjects is a risk factor for coronary heart disease in them. ${ }^{12,21}$

The significant low serum levels of Sodium and Calcium observed in this study agrees with the findings of the work done by Magak; Ugwuja and Eze in which they found significant decrease in these electrolytes in HIV- positive subjects compared with the control. ${ }^{34,39}$ The non-significance difference in this study of the serum levels of Potassium, Bicarbonate and Chloride between the HIV positive subjects and the normal control is in consonance with the results obtained by Magak that there was no significance difference $(\mathrm{p}<0.05))$ in the serum levels of these electrolytes in the HIV positive subjects when compared with the control. ${ }^{34}$ However, the results obtained for Potassium, Bicarbonate and Chloride in HIV positive patients by Ugwuja and Eze contradicts this finding. They found the levels of these electrolytes in the HIV patients to be significantly reduced $(\mathrm{p}<0.05)$ compared with the control. $^{39}$ HIV infected patients and especially those with AIDS are predisposed to a multitude of different water, electrolytes and acid-base disorders since they are exposed to infectious, inflammatory, oncological and pharmacological variables whose combination undermine their homeostatic capability. ${ }^{40}$

\section{Conclusion}

The findings of this study indicate that there are significant changes in biochemical parameters including serum liver enzymes and lipid profile in HIV infected subjects.

\section{Recommendation}

Since HIV infection is associated with changes in biochemical parameters, there is therefore the need for routine monitoring of these parameters among HIV infected subjects. 


\section{References}

1. Rasool S T; Tang H; Wu J; Li W; Muktar M M; Zhang $\mathrm{J}$ et al. Increased level of IL-32 during human immunodeficiency virus infection suppresses HIV replication. Immunol. Lett. 2008: 117:161-167.

2. Wihelm K. Encyclopedia of public health, New York: Springer. 2008: 676-677.

3. Alexander K; Mirjani K; Klaus K. Modern infectious diseases epidemiology concepts methods mathematical models and public health. New York. 2010: 88.

4. Sepkowitz KA. AIDS- The first 20 years. N. Eng. J. Med. 2012:344(23): 1764-1772.

5. Ocheni S; Aken'ova YA. Association between HIV/AIDS and malignancies in a Nigerian Tertiary Institution. West African Journal of Medicine. 2004: 23(2): 151-155.

6. Stephens W S; Scott L M; Crowe S M. Quantifying HIV for monitoring antiretroviral therapy in resonance poor settings. J. Infect. Dis. 2010: 201 (1): 16-26.

7. Bartholomew O I; Olusola D O; Urena I; Josiah $\mathrm{B} \mathrm{H}$. Biochemical and haematological changes in HIV subjects receiving winniecure antiretroviral drug in Nigeria. Journal of Biomedical Science. 2013: 20(1): 73.

8. Afhami S; Rasolinejad M; Razghi E; Shahriari S; Esmailpour N. Renal disorder in HIV- infected patients. Achives of Iranian Medicine. 2007: 10(3): 335-338.

9. Roling J; Schmid H; Fischereder M; Draenert R; Goebel F D. HIV-associated renal disease and highly active antiretroviral therapy induced nephropathy. Clin. Infect. Dis. 2008: 42: 14881495.

10. Ridler S A; Smit E; Cole S R. Impact of HIV infection on serum lipids in men. JAMA. 2003:289:2978-2982.

11. Moudy K; Overton E T; Grubb I. Metabolic syndrome in HIV- infected patients from urban mid western US out-patient population. Clin. Infect. Dis. 2007: 144: 726-734.

12. Buchacz K; Weidle P J; Moore D. Changes in lipid profiles over 24 months in adults on first line highly active antiretroviral therapy in home based care in rural Uganda. J. Acquir. Immune Defic. Syndrome. 2008: 47 (33): 594-600.
13. Egger M; May M; Chene G; Hirsel B; Horber W; Li L S. Prognosis of HIV-1 infected patients staring highly active antiretroviral therapy. A collaborative analysis of prospective studies. Lancet. 2002: 60: 119-129.

14. Nunez M. Hepatotoxicity of antiretrovirals: Incidence, mechanism and management. J. Hepatol. 2006: 44(1): 132-139.

15. Pol S; Lebray P; Vallet-Pichard A. HIV infection and hepatic enzymes abnormalities: Intricacies of the pathogenic mechanisms. Clin. Infect. Dis. 2004: 38 (2): 65-72.

16. Robert A N; David O; George A. Effects of HIV infection and highly active antiretroviral therapy (HAART) in the liver of HIV patients. Trends in Medical Health Science. 2015: 10: 1-11.

17. Zechini B; Pasquazzi C; Aceti A. Correlation of serum aminotransferases with HVC RNA levels and histological findings in patients with chronic hepatitis $\mathrm{C}$ : the role of serum aspartate transaminase in the evaluation of disease progression. Eur. J. Gastroenterol. Hepatol. 2004: 16(9): 891-896.

18. Sterling R K; Sulkowski M S. Hepatitis C virus in the setting of HIV or hepatitis B virus coinfection. Semin Liver Dis. 2004: 24(2): 61-68.

19. Palmon R; Koo B C; Shoultz D A; Dieterich D T. Lack of hepatotoxicity associated with nonnucleoside reverse transcriptase inhibitors. J. Acquir. Immune Defic. Syndr. 2002: 29(4):340345.

20. UNAIDS. Report on the global AIDS epidemics UNAIDS $10^{\text {th }}$ Anniversary Special Edition, Geneva.

21. Mahendra R P; Trupti R; Arun T. Changes in lipid profile and liver enzymes in HIV infection and AIDS patients. International Journal of Scientific and Research Publication. 2015: 5(9): $1-5$.

22. Diana G; Meropi A; Sebasteim J; Rosaline T; Nina D; Natalia $G$ et al. Sex hormones selectively impact the endocervical mucosal microenvironment: Implications for HIV transmission. 2014: PLOS.9:e97767.Dio:101371.

23. Brahamareddy M P; Bharita P; Shah R M; Nillawar A N; Madhu L; Durgabharanireddy V et al.Changes in lipid profiles and other biochemical parameters in HIV-1 infected 
patients. International Journal of Medicinal Science and Public Health. 2014:3(7)

24. Mgogwe J; Semna H; Msangi R; Mataro C; Kajeguka D. The evolution of haematological and biochemical indices in HIV patients during a six month treatment period. African Health Sciences. 2012:12(1):2-7.

25. Kredo T; Vander W J S; Siegfried N; Cohen K. Therapeutic drug monitoring of antiretrovirals for people with HIV. Cochrane Database Syst. Rev. 2008: (3): ID007268.

26. Pryce C; Pierre R B; Steel-Duncan J; EvansGilbert T; Palmer P; Moore J. Safety of antiretroviral drug therapy in Jamaican children with HIV/AIDS. West Indian Journal. 2008: 57(3): 238-245.

27. Karlsson H G B; Fouchier R A; Phagot S; Burton D R; Sodroski J; Wyatt R T. The changes of eliciting neutralizing antibodies. Rev. Microbiol. 2008: 6(2):143-155.

28. Ene A C; Gadzama A A; Idigbe E O. Serum enzymes levels in HIV/AIDS patients in Maiduguri, North Eastern Nigeria. J. Med. Science. 2006: 6(5): 878-880.

29. Ranjit P; Uplabdhi R. Serum albumin, globulin levels and $\mathrm{A} / \mathrm{G}$ ration in HIV positive patients. Biochemical and Pharmacology Journal. 2009: 2(2): Available from:http//biomed pharmajournal.org.

30. Ogunro P S; Oparinde D P; Okesina A B. Liver function tests in HIV-1 infected asymptomatic patients and HIV-1/AIDS patients without hepatomegaly in Lagos, Nigeria. Afr. J. Clin. Exp. Microbiol. 2005.6:40-45.

31. Drain P K; Kupka R; Mugusi F; Fawzi W W. Micronutrients in HIV positive persons receiving HAART. American Journal of Clinical Nutrition.2007: 85 (2): 333-345.

32. Sarro Y S; Tounkara A; Tangara E; Guindo O; White $\mathrm{H}$ L; Chammot $\mathrm{E}$ et al. Serum electrophoresis. Role in monitoring for ART. African Health Science. 2010: 10(2):138-143.

33. Magak A G N. Kidney function predictors and associated serum electrolytes changes in HIV out-patients attending Jaramoyi Oginga Oding Teaching and Referral Hospital, Kisumu County, Kenya. East African Medical Journal. 2015: 92(12):442-453.

34. Szczech L A. Renal diseases associated with human immunodeficiency virus infection; epidemiology, clinical course and management. Clin. Infect. Dis. 2001: 33:115-119.

35. Palanisamy P; Govindaswamy B; Ganesan S. Changes in CD4 cell count, lipid profile and liver enzymes in HIV infection and AIDS patients. J. Appl. Biomed. 2008:6:139-145.

36. Adewole O O; Eze S B; Betiku Y E; Anteyi E; Wada I; Ajuwon $\mathrm{Z}$ et al. Lipid profile in HIV/AIDS patients in Nigeria. Afr. Health Sci. 2010: 10(2): 144-149.

37. Bernal E; Masia M; Padilla S; Gutierre Z F. High density lipoprotein cholesterol in HIV infected patients. Evidence of an association with HIV-1 viral load, antiretroviral therapy status and regimen composition in AIDS patient care and STD $_{\mathrm{S}}$.2008: 22:1-7.

38. Grinspoon S; Carr A. Cardiovascular risk and body fat abnormalities in HIV infected adults. The New England Journal of Medicine.2005:352:48-62.

39. Ugwuja E; Eze N. A comparative study of serum electrolytes, total protein, calcium and phosphate among diabetic and HIV/AIDS patients in Abakaliki, South Eastern Nigeria. The International Journal of Laboratory Medicine. 2006:2(1):56-67

40. Carlos G M; Waldo H B; Richard J G. Water, electrolytes and acid-base alterations in human immunodeficiency virus infected patients. World Journal of Nephrology. 2016: 5(1):33-42. 